\title{
Biological and technical study of a partial-SHARON reactor at laboratory scale: effect of hydraulic retention time
}

\author{
A. González-Martínez • K. Calderón • \\ A. Albuquerque · E. Hontoria · J. González-López • \\ I. M. Guisado • F. Osorio
}

Received: 26 April 2012 / Accepted: 9 June 2012

(C) Springer-Verlag 2012

\begin{abstract}
This study was on the technical and biological characteristics of a partial-SHARON submerged-filter bioreactor of $3 \mathrm{~L}$. The main focus was the influence of the hydraulic retention time (HRT) on biofilms. For this purpose, we used molecular tools based on the partial $16 \mathrm{~S}$ rRNA genes. The results showed that the HRT may affect the nitrification processes of a bioreactor using synthetic wastewater containing $600 \mathrm{mg} / \mathrm{L}$ of ammonia. It was found that an HRT of 0.5 day transformed $100 \%$ of the ammonium into nitrite. However, when the HRT was decreased to 0.4 day, there was a significant reduction $(35 \%)$ in the quantity of ammonia transformed, which confirmed the complexity of the system operation. Moreover, a PCRTGGE approach highlighted the differences observed. The results obtained showed that an HRT of 0.5 day reduced bacterial biodiversity in the biofilms, which were mainly formed by Nitrosomonas and Diaphorobacter. In contrast, an HRT of 0.4 day facilitated the formation of heterogeneous biofilms formed by nitrifying bacteria, such as Nitrosomonas sp., Nitrosospira sp., and Nitrosovibrio sp.).
\end{abstract}

A. González-Martínez · E. Hontoria · F. Osorio ( $₫)$ Department of Civil Engineering, University of Granada, Campus de Fuentenueva, s/n, 18071 Granada, Spain e-mail: fosorio@ugr.es

A. González-Martínez · K. Calderón · E. Hontoria · J. González-López · I. M. Guisado · F. Osorio Institute of Water Research, University of Granada, Granada, Spain

A. Albuquerque

Department of Civil Engineering and Architecture,

University of Beira Interior, Covilha, Portugal
Keywords SHARON process - Partial nitrification · Hydraulic retention time (HRT) - Wastewater treatment . Submerged biofilter $\cdot$ Nitrogen removal

\section{Introduction}

In the last 10 years, soaring population levels as well as a corresponding growth in industrial activity have led to increased amounts of wastewater in densely populated areas. This surfeit of waste is having an extremely negative impact on the environment. For example, high concentrations of nitrogen, one of the main compounds in wastewater, cause serious environmental problems such as oxygen depletion and eutrophication [1]. The EU Water Framework Directive 91/271/EEC clearly requires EU member states to protect the environment from any adverse effects due to the discharge of (untreated) urban and industrial waters. In this context, new technologies, such as the partial-SHARON/ Anammox process, provide a cost-effective way to treat highly contaminated effluent $[1,2]$. This combined process is an excellent alternative to conventional nitrificationdenitrification processes since it reduces the organic matter $(40 \%)$ and oxygen $(25 \%)$ required for ammonia removal in comparison to more conventional technologies [3].

In order to fully understand the biodiversity of biological wastewater treatments, it is first necessary to identify the microbiota present and analyze their numerical significance. Culture-dependent methods have sometimes been regarded as inadequate for the analysis of microbial communities in natural environments because of the high numbers of unculturable bacteria. Furthermore, in recent years, molecular methods, based on the sequencing of PCR-amplified the partial 16S rRNA genes from DNA extracted from environmental samples, have been widely used to reveal intrinsic 
genetic biodiversity [4]. In particular, denaturing gradient gel electrophoresis (DGGE) and temperature gradient gel electrophoresis (TGGE) approaches yield large quantities of data regarding the diversity of microorganisms in their natural habitats. This has the advantage of permitting the taxonomic classification of community members [5].

The single reactor system for high-activity ammonia removal over nitrite (SHARON) process was described in detail by Hellinga et al. [6], who proposed the partialSHARON technology. The partial-SHARON process is a modification of the traditional SHARON process, in which $100 \%$ of the ammonium is converted into nitrite. In contrast, the partial-SHARON process, as its name implies, consists of a partial nitritation. More specifically, only $50 \%$ of the ammonium is converted to nitrite. This process was developed for the elimination of ammonium by the "nitrite route" [7]. When the partial-SHARON process is used in combination with the Anammox process, nitrogen removal takes place in two steps. According to Van Dongen et al. [8], the Anammox process achieves an optimal performance with an ammonium-nitrite mixture of $50 \%$ ammonium and $50 \%$ nitrite. For this reason, the Anammox process has to be preceded by a partial-SHARON process involving a partial nitrification.

Molecular techniques have been used to provide a broader vision of the different biotechnological systems in wastewater treatment as shown in recent studies (e.g., [4]). These techniques have been used to obtain a wide range of data regarding microbiota in their habitats. In fact, they facilitate the study of non-cultivable bacteria by specifying the microbial populations that carry out these processes $[9,10]$. For this reason, this research analyzed the following: (1) the hydraulic retention time (HRT) in a partialSHARON reactor in which submerged filters were used to remove nitrogen; (2) the effect of the HRT on the structure of the bacterial community. In our study, molecular fingerprinting tools (PCR-TGGE) and scanning electron microscope (SEM) were used to evaluate the structure of the bacterial community.

\section{Materials and methods}

The SHARON bioreactor: bench-scale plant

The bench-scale plant used in our experiments consisted of a plastic SHARON bioreactor with a volume of $3 \mathrm{~L}$. It was constructed as a submerged biofilter with PVC carriers (BioFlow 9). A schematic diagram of the experimental plant is shown in Fig. 1. The bioreactor received synthetic wastewater [2] from a peristaltic pump, and was operated in continuous flow.

The operating conditions in the bioreactor (i.e., HRT, $\mathrm{pH}$, dissolved oxygen concentration, and temperature) were monitored every $24 \mathrm{~h}$ in order to verify that they remained stable. Four $15-\mathrm{cm}$ air diffusers at the bottom of the vessel supplied oxygen from an air pump to ensure that the oxygen concentration in the bioreactor was maintained at $2 \mathrm{mg} / \mathrm{L}$. All of the experimental work was performed at a $\mathrm{pH}$ of 7.5 and a temperature of $35^{\circ} \mathrm{C}[11,12]$, thanks to an adjustable thermostat.

Inoculation of the pilot plant

The partial-SHARON bioreactor was inoculated with mixed liquor from an aerobic reactor located in the Los Vados urban wastewater treatment plant (Granada, Spain). The mixed liquor was recirculated for 3 days until a biofilm formed on the surface of the plastic carriers used in the construction of the submerged biofilter. After inoculation, synthetic wastewater was fed into the bioreactor.

\section{Synthetic wastewater}

The synthetic wastewater [2] used in our study simulated the leachate from an anaerobic digester, since it contained a high concentration of ammonium and was low in organic matter (see Table 1).

To prepare the synthetic wastewater, $24 \mathrm{~L}$ of distilled water was poured inside the $60-\mathrm{L}$ tank along with the exact quantity of the chemical compounds that made up the synthetic sewage medium. All components were then mixed and dissolved. The influent was continuously fed into the bioreactor by a peristaltic pump (Watson Marlow s-520) that pumped the synthetic wastewater at different flow rates.

\section{Physico-chemical parameters}

The physico-chemical parameters analyzed in our study were the following: $\mathrm{pH}$, dissolved oxygen concentration, temperature, and nitrogen concentration in its various

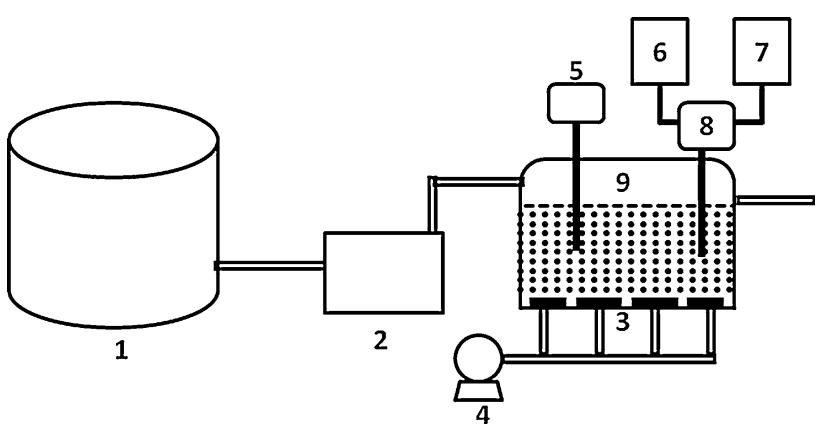

Fig. 1 Diagram of the pilot-scale partial-SHARON bioreactor used in the experiments. 1 Synthetic wastewater tank; 2 peristaltic pump; 3 oxygen diffusers (porous plates); 4 air pump; 5 thermostat; 6 tank of $\mathrm{NaOH} 0.1 \mathrm{M}$ for pH control; 7 tank of $\mathrm{H}_{2} \mathrm{SO}_{4} 0.1 \mathrm{M}$ for $\mathrm{pH}$ control; 8 pH meter; 9 partial-SHARON bioreactor stuffed with carriers 
Table 1 Composition of the synthetic wastewater in $\mathrm{g} / \mathrm{L}$ used in the experiments

\begin{tabular}{ll}
\hline Chemical & $\mathrm{g} / \mathrm{L}$ \\
\hline$\left(\mathrm{NH}_{4}\right)_{2} \mathrm{SO}_{4}$ & 2.35 \\
$\mathrm{NaHCO}_{3}$ & 3.25 \\
$\mathrm{CaCl}_{2}$ & 0.30 \\
$\mathrm{KH}_{2} \mathrm{PO}_{4}$ & 0.07 \\
$\mathrm{MgSO}_{4}$ & 0.02 \\
$\mathrm{FeSO}_{4} \cdot 7 \mathrm{H}_{2} \mathrm{O}$ & 0.009 \\
$\mathrm{H}_{2} \mathrm{SO}_{4}$ & 0.005 \\
\hline
\end{tabular}

Table 2 Conditions of the partial-SHARON bioreactor in experiments 1 and 2

\begin{tabular}{llll}
\hline Parameter & Experiment 1 & Experiment 2 & References \\
\hline Oxygen demand $(\mathrm{mg} / \mathrm{L})$ & 1.5 & 1.5 & {$[13]$} \\
$\mathrm{pH}$ & 7.5 & 7.5 & {$[14]$} \\
Temperature $\left({ }^{\circ} \mathrm{C}\right)$ & 35 & 35 & {$[3]$} \\
HRT (days) & 0.5 & 0.4 & \\
\hline
\end{tabular}

inorganic forms (ammonium, nitrite, and nitrate). Samples were taken every $24 \mathrm{~h}$ because of the slow growth of ammonia-oxidizing bacteria [8].

In constant $\mathrm{pH}$, oxygen, and temperature conditions, two experiments were performed at different HRTs $(0.4$ and 0.5 day) with a view to analyzing the evolution of inorganic nitrogen concentration in the bioreactor and also the microbial diversity in the biofilm. Table 2 shows the conditions of both experiments.

$p H$

The $\mathrm{pH}$ was measured directly in the bioreactor at 8 -h intervals, using a pH meter (Crison GLP 91) [15]. The equipment was adjusted daily with buffer solutions of $\mathrm{pH}$ 4.0 and 7.0 .

\section{Dissolved oxygen concentration}

The dissolved oxygen concentration in the bioreactor was determined by means of a pulse oximeter (CRUCIBLE OXI320), which was calibrated according to the manufacturer's instructions.

\section{Determination of ammonium, nitrite, and nitrate}

Concentrations of the various inorganic forms of nitrogen (nitrite, nitrates and ammonium) were measured daily at the entry and exit points of the partial-SHARON bioreactor with an ionic chromatograph Metrohm. Nitrite and nitrate levels were measured with an anion column Metrosep A supp-4-250, and ammonium levels, with a cation column
Metrosep C 2-150. A carbonate/bicarbonate solution was used as an eluent. Calibration curves of known concentrations of ammonium, nitrite, and nitrate $(10,500$ and $1,000 \mathrm{mg} / \mathrm{L}$ ) were also analyzed daily.

DNA extraction and PCR amplification of partial bacterial $16 \mathrm{~S}$ rRNA genes

DNA was extracted from the biofilm that formed in the submerged biofilter. This was done by vortexing approximately $200 \mathrm{~mL}$ of plastic carriers from the biofilters with a saline solution, and then centrifuging them to obtain the biofilm fraction. Samples (approx. $200 \mathrm{mg}$ ) from the biofilm were collected with the FastDNA Kit and the FastPrep24 apparatus (MP-BIO, Germany).

Polymerase chain reaction (PCR) amplification was performed in two steps, following other research on TGGE and DGGE fingerprinting [4, 9]. One microliter (2-5 ng) of the DNA extracted was used as a template for all the PCRs. At the first PCR, the template was diluted 1:10. Highperformance liquid chromatography (HPLC)-purified oligonucleotides were purchased from Sigma. AmpliTaq Gold polymerase (Applied Biosystems, Life Technologies, Carlsbad, CA, USA) was used for all PCRs, which were performed in an Eppendorf Master Cycler (Eppendorf, Hamburg, Germany). Primers and conditions for each of the PCR reactions were those described in Molina-Muñoz et al. [9]. The final PCR products were cleaned and/or concentrated (when required) using Amicon Ultra- $0.5 \mathrm{~mL}$ Centrifugal Filters (Eppendorf, Hamburg, Germany). Ten microliters (60-100 ng DNA) were loaded into each well for TGGE.

\section{TGGE analysis}

TGGE was performed using a TGGE Maxi system (Whatman-Biometra, Goettingen, Germany). The denaturing gels (6\% polyacrylamide [37.5:1 acrylamide:bisacrylamide], $20 \%$ deionized formamide, $2 \%$ glycerol, and $8 \mathrm{M}$ urea) were prepared and run with $2 \times$ Tris-acetateEDTA buffer. All chemicals were purchased from Sigma Aldrich (St. Louis, MO, USA). The temperature gradient was optimized at $43-63{ }^{\circ} \mathrm{C}$ [9]. The bands were visualized by silver staining with the Gel Code Silver Staining kit (Pierce, Thermo Fisher Scientific, Rockford, IL, USA). Various PCR reactions were tested, and different TGGE gels were run to check the reproducibility of the results.

\section{Analysis of TGGE fingerprints}

The band patterns generated by TGGE were normalized, compared, and clustered by using the Gel Compar II v. 5.101 software (Applied Maths, Belgium). For cluster 
analysis, the TGGE profile was compared by means of a band assignment independent method (Pearson productmoment correlation coefficient) as well as a method based on band presence/absence (Dice coefficient). In reference to band assignment, a $1 \%$ band position tolerance (relative to the total length of the gel) was applied [4]. Dendrograms relating band pattern similarities were automatically calculated with unweighted pair group method with arithmetic mean (UPGMA) algorithms. The significance of UPGMA clustering was estimated by calculating the cophenetic correlation coefficients.

Range-weighted richness indices $\left(R_{\mathrm{r}}\right)$, which estimate the level of microbial diversity in environmental samples, were calculated, based on the total number of bands in each TGGE pattern $(\mathrm{N})$ and the temperature gradient $\left({ }^{\circ} \mathrm{C}\right)$ between the first and last band of each pattern $(\mathrm{Tg})$, following Marzorati et al. [16]. The resulting values were divided by 100 [5] to keep an order of magnitude analogous to that of the $R_{\mathrm{r}}$ index, as originally described for DGGE in Marzorati et al. [16].

Pareto-Lorenz distribution curves rendered a graphical representation of the evenness of the bacterial communities in the different samples, based on the TGGE fingerprints [16]. The bands in each TGGE lane were ranked from highest to lowest based on intensity levels. The cumulative normalized band intensities for each TGGE lane were plotted against their respective cumulative normalized number of bands. The curves were numerically interpreted by the functional organization index $\left(F_{\mathrm{o}}\right)$, given by the horizontal $y$-axis projection on the intercept with the vertical $20 \% x$-axis line [16]. The calculation of the $F_{\mathrm{o}}$ indexes permitted the evaluation of the functional redundancy of the microbial communities analyzed by fingerprinting methods [16].

\section{DNA reamplification and sequencing}

Portions of individual bands on silver-stained TGGE gels were picked up with sterile pipette tips, placed in $10 \mu \mathrm{L}$ of filtered autoclaved water, and $3 \mu \mathrm{L}$ of the resulting DNA suspensions were used for reamplification with the appropriate primers. The PCR products were electrophoresed in agarose gels and purified with the Qiaex-II kit (Qiagen, Hamburg, Germany). The recovered DNA was directly used for automated sequencing in an ABI PRISM 3100 Avant Genetic Analyzer (Life Technologies, CA, USA).

Bacterial community analysis

The DNA sequences were analyzed and compared with the biocomputing tools provided online by the National Center for Biotechnology Information (http://www.ncbi.nlm.nih. gov). Sequence similarity analysis was performed with the
BLASTn program [17]. ClustalX v. 2.0.3 software was used for the alignment of the DNA sequences. The graphical distribution of the main bacterial groups found is shown in this article.

Scanning electronic microscopy

The biofilm formed in the submerged biofilter was analyzed by scanning electron microscopy (SEM). Individual pieces of plastic carriers from the biofilter were fixed with glutaraldehyde $(5 \% \mathrm{v} / \mathrm{v})$ in a $0.2 \mathrm{M}$ sodium cacodylate buffer ( $\mathrm{pH} 7.1$ ), washed, and post-fixed in $\mathrm{OsO}_{4}$, before being dehydrated with graded ethanol solutions $(10,30,50$, 70, 90, and $100 \%$ ethanol). All chemicals were purchased from Sigma-Aldrich (St. Louis, MO, USA). The samples were transferred to fresh $100 \%$ ethanol and critical pointdried from liquid carbon dioxide at $36.1^{\circ} \mathrm{C}$ and 7.37 Pa, using a Samdri 780B apparatus (Tousimis, Rockville, USA). Samples were coated with gold before being examined by variable pressure scanning electron microscopy (VP-SEM), model LEO 1430VP-SEM.

\section{Results and discussion}

Physico-chemical parameters at different HRT

\section{Experiment 1: HRT of 0.5 day}

The partial-SHARON bioreactor was fed with synthetic wastewater at a constant flow rate of $4.16 \mathrm{~mL} / \mathrm{min}$ and an HRT of 0.5 day. The concentration of ammonium, nitrate, and nitrite was measured at the entry and exit points of the system. These results are shown in Fig. 2.

As can be observed in Fig. 2, after 5 days of operation, $100 \%$ of the ammonium was converted to nitrite. After this period, the partial-SHARON bioreactor stabilized and maintained its high capacity for biotransformation. However, the higher nitrite concentration caused a sharp drop in the $\mathrm{pH}$ of the bioreactor. To correct this, it was necessary to add small amounts of $\mathrm{NaOH} 1 \%(\mathrm{p} / \mathrm{v})$, which kept the $\mathrm{pH}$ value at 7.5 .

When the biotransformation capacity of ammonium into nitrite in submerged biofilters was compared with that of other systems such as conventional partial-SHARON bioreactors $[8,12]$, the results showed that submerged biofilters have higher levels (three times higher) of biotransformation. The high transformation capacity of submerged-biofilter systems should be regarded as an important operational factor for the development and future design of partial-SHARON/ Anammox systems, which can be applied to the treatment of effluents with high nitrogen content such as landfill leachate [18]. 


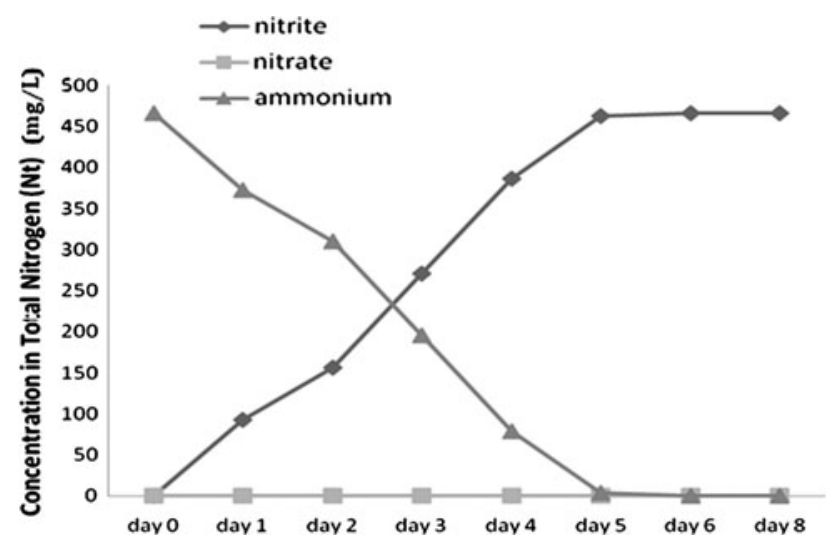

Fig. 2 Values of ammonium and nitrite expressed as total nitrogen detected in the effluent of a partial-SHARON bioreactor over time with an HRT of 0.5 day

\section{Experiment 2: HRT of 0.4 day}

Experiment 2 was performed at an HRT of 0.4 day and a constant flow rate of $5.20 \mathrm{~mL} / \mathrm{min}$ of synthetic wastewater. In the same way as in experiment 1 , the concentration of ammonium, nitrate, and nitrite was measured at the entry and exit point of the partial-SHARON bioreactor. The results are shown in Fig. 3.

As can be observed in Fig. 3, the transformation of ammonium into nitrite reached $60 \%$ after 5 days of operation. After this period, the partial-SHARON bioreactor stabilized, and its capacity for the biotransformation of ammonia to nitrite remained constant. The increased nitrite concentration caused a sharp drop in the $\mathrm{pH}$ level of the bioreactor. To correct this, it was necessary to add small amounts of $\mathrm{NaOH} 1 \%(\mathrm{p} / \mathrm{v})$ to maintain the $\mathrm{pH}$ value at 7.5 .

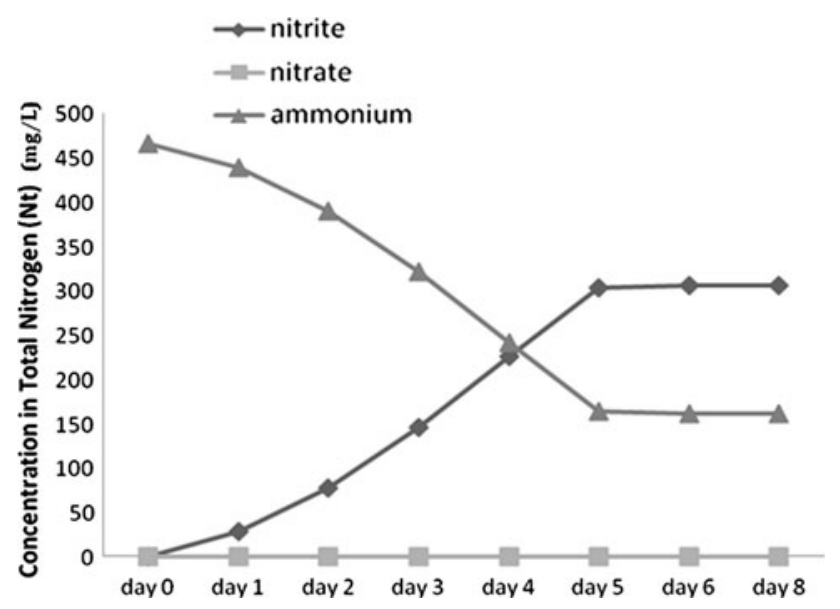

Fig. 3 Values of ammonium and nitrite expressed as total nitrogen detected in the effluent of a partial-SHARON bioreactor over time with an HRT of 0.4 day
The results obtained in the submerged-biofilter partialSHARON system showed that working at experimental conditions of temperature $\left(35^{\circ} \mathrm{C}\right)$, oxygen concentration $(1.5 \mathrm{mg} / \mathrm{L}), \mathrm{pH}(7.5)$, and HRT from 0.5 to 0.4 days, an evident reduction in the biotransformation of ammonium to nitrite was observed when the HRT was decreased. When the bioreactor was operating at an HRT of 0.5 day, $100 \%$ of the ammonium was converted to nitrites, whereas when the bioreactor was operating at an HRT of 0.4 day, only $60 \%$ of the ammonium was converted to nitrites. However, undetectable amounts of nitrates were produced at the exit point of the partial-SHARON bioreactor. This low capacity of transformation of ammonium to nitrate in the bioreactor can be due to the operational conditions of the system that increase the biological activity of the ammonium-oxidizing bacteria and decrease the biological activity of the nitrite-oxidizing bacteria. In this sense, according to the bacterial community analysis obtained in our study (described below), the use of an HRT of 0.5 days, determined the production of highly specialized biofilms mainly integrated by Nitrosomonas sp., which are very effective in the oxidation of ammonium into nitrite.

According to Van Dongen et al. [8], the optimal ammonium and nitrite ratio in the effluents in partialSHARON systems for their combination with Anammox bioreactors is $50 \%$ ammonium and $50 \%$ nitrite. In this context, our data suggest that in submerged-biofilter partial-SHARON systems, the ammonium-nitrite ratio can be modified by the HRT. Moreover, the results obtained in our experiments show that the submerged-filter technology applied to partial-SHARON processes increased the transformation of ammonium into nitrite and decreased the time required for the start-up of the bioreactors. This is evident when the data obtained in submerged-biofilter systems are compared with other technologies [12, 18, 19].

Study of the bacterial diversity in the partial-SHARON bioreactor

The structure of bacterial communities was analyzed by TGGE fingerprinting. The prevalent TGGE bands indicated the phylogenetic groups. The sequencing of the TGGE bands revealed that the prevalent bacteria populations were developmentally close to Proteobacteria and specifically to Alphaproteobacteria, Betaroteobacteria, Gammaproteobacteria, and Deltaproteobacteria. The bacteria populations in the partial-SHARON bioreactor varied, depending on operational conditions. Accordingly, the PCR-TGGE method showed significant differences in the structure of the bacteria community at HRTs of 0.5 and 0.4 day (see Fig. 4). The Pearson coefficient-based analysis permitted the identification of four clusters corresponding to the different treatments analyzed. On the other hand, the Dice 


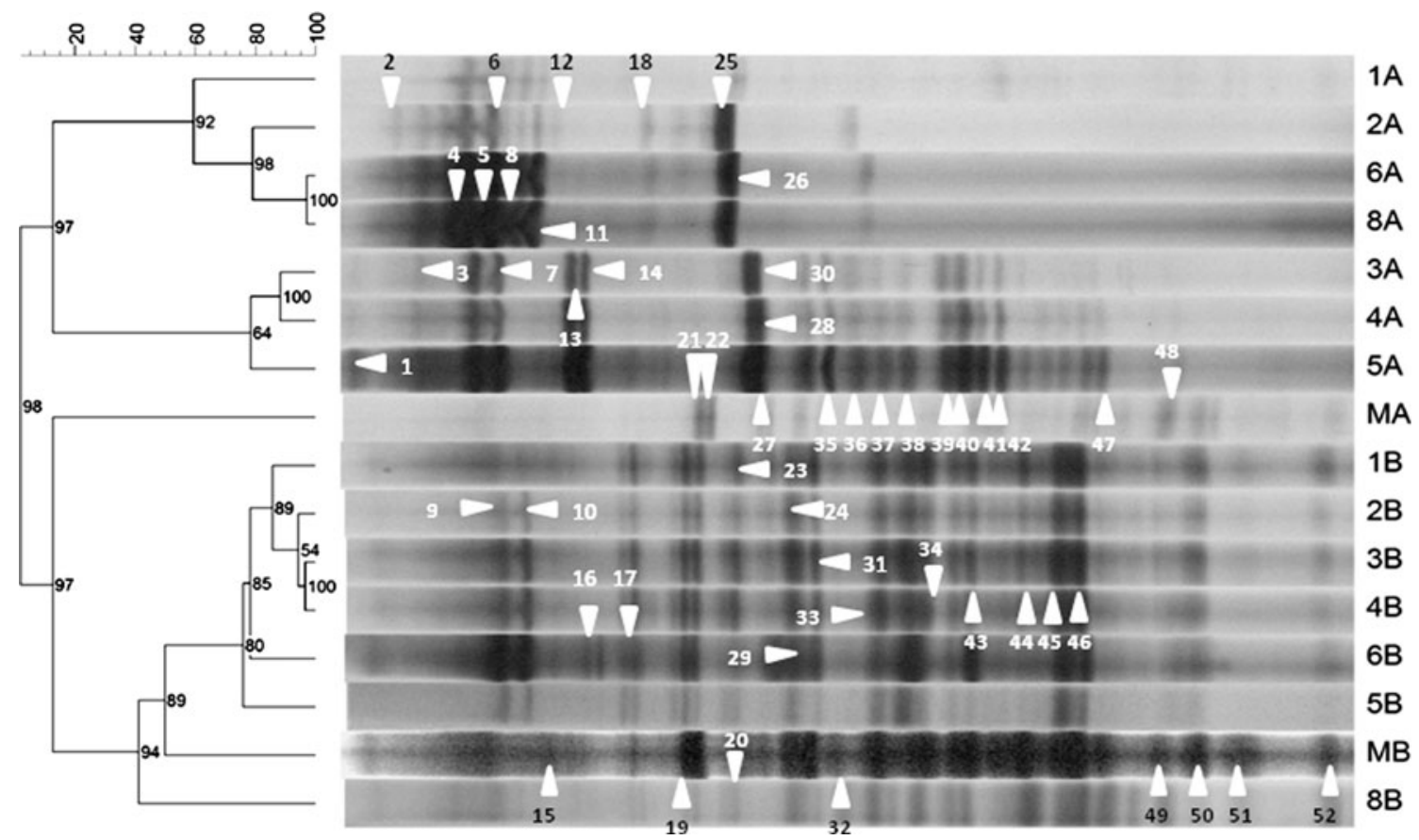

Fig. 4 Pearson coefficient-based analysis of the band patterns generated from 52 samples analyzed in the partial-SHARON bioreactor. Samples named with letter $A$ corresponds to the first experiment and letter $B$ corresponds to the second experiment. The numbers indicate the days on which samples were extracted from the bioreactor. $M A$ and $M B$ samples were taken at the beginning of the first and second experiment, respectively, related to zero time

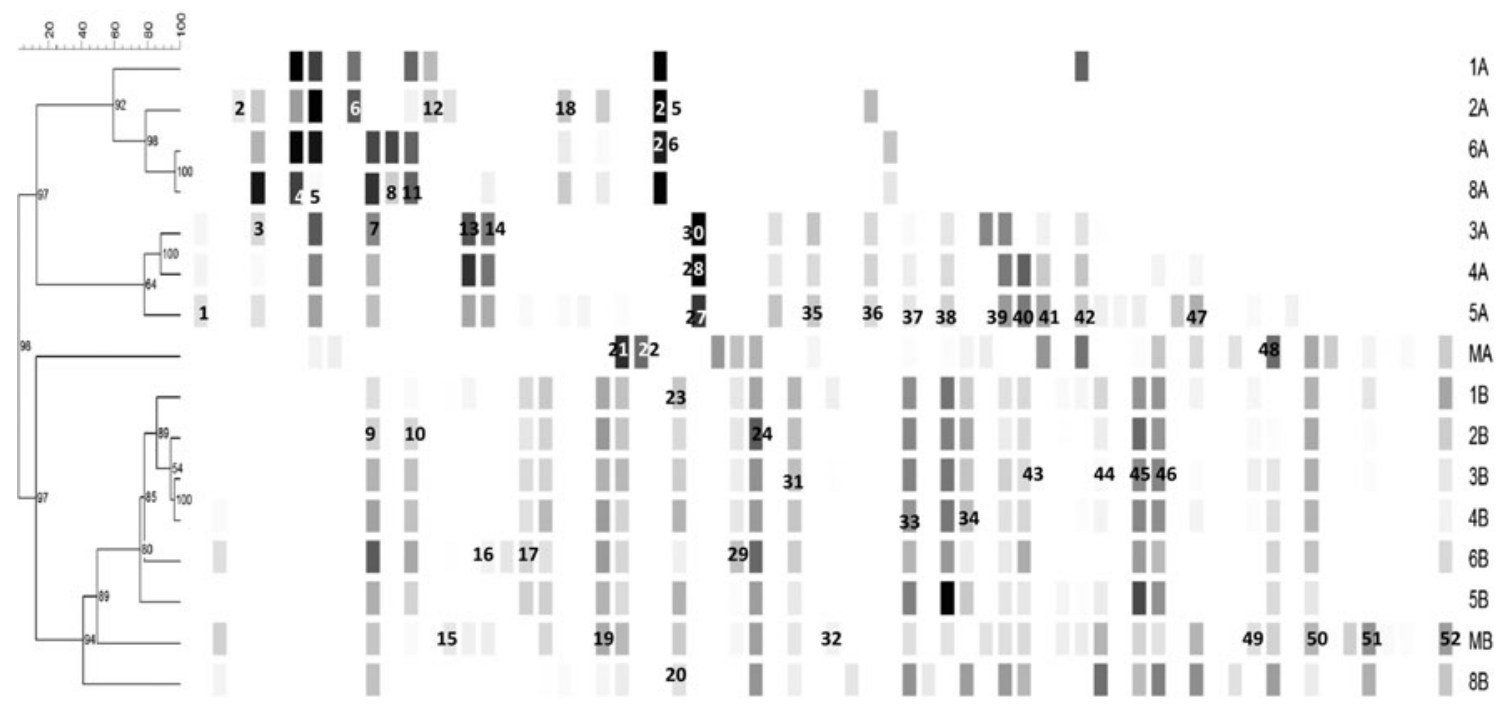

Fig. 5 Dice coefficient-based analysis of band patterns generated from all samples analyzed with a presence/absence matrix

coefficient was used to obtain 66 unique band classes in both experiments (see Fig. 5).

\section{Study of biofilms formed at an HRT of 0.5 day}

The TGGE profiles demonstrated that when the partialSHARON system operated at an HRT of 0.5 day, a significant number of bands disappeared $48 \mathrm{~h}$ after its start-up
(Fig. 4). For example, bands 21 and 22 related to Pseudacidovorax sp. and Aquaspirillum sp., vanished completely. However, after 2 days of operation, new bands were detected in the TGGE gels. Finally, the PCR-TGGE studies showed how the bacteria populations of the biofilms in the partial-SHARON system began to stabilize after 4 days of operation. Moreover, some bands gained in intensity over time, such as bands 4 (Nitrosomonas 
eutropha), 14 (Variovorax sp.), and 27 (Nitrosomonas europaea).

After the stabilization of the partial-SHARON bioreactor ( 5 days after the pilot plant start-up), when $100 \%$ of the ammonium was converted into nitrite, there was a significant decrease in the bacterial biodiversity of the biofilms in the submerged biofilter. Consequently, bands $38,39,40,41,42$ and 47 were no longer detected in the TGGE gels (Fig. 4). In contrast, certain bands, such as 4 and 11 (N. europaea and N. eutropha), gained in intensity. In addition, a new band (band 8) appeared that was related to Diaphorobacter sp.

According to Khan and Hiraishi [20], and Anshuman et al. [21], Diaphorobacter sp. is an interesting bacteria in nitrogen removal processes. Nevertheless, to our knowledge, this is the first time that these microorganisms have been observed in a partial-SHARON bioreactor. Furthermore, our data showed that $N$. europaea and N. eutropha, which have a great affinity for ammonium, were prevalent over the rest of the ammonium-oxidizing bacteria [22, 23].

Samples 1A and 2A were collected from the partialSHARON bioreactor when the concentration of ammonium was high and the concentration of nitrite very low. They showed a balanced community with low microbial diversity (Fig. 4). Similar results were obtained in samples 6A and $8 \mathrm{~A}$, which were taken from the bioreactor when the concentration of ammonium was very low and the concentration of nitrite was high (Fig. 4). This reflects that in extreme environments of high concentrations of ammonium or nitrite, microbial diversity decreases in the biofilms in order to preserve its functionality in changing environmental conditions.

The Pearson coefficient-based analysis (Fig. 4) allowed for the identification of two separate clusters of Bacteria, which corresponded to samples taken at two different sampling times: the start-up point and the stabilization point of the bioreactor. The sample taken at the start-up point clustered at $60 \%$ and the one taken at the stabilization point clustered at $80 \%$, which indicated a good relationship between the compositions of the two bacteria cluster communities. Cluster analysis based on the Dice coefficient (Fig. 5) showed the same results as the Pearsonbased clustering.

A total of 24 bands selected from the TGGE fingerprints targeting bacteria were successfully amplified and sequenced from TGGE gels (Table 3), corresponding to the dominant bacteria populations in biofilms formed in the partial-SHARON bioreactor. A prevalence of Proteobacteria in the set of sequences analyzed was found in the sampling periods. The main group of identifiable TGGE bands was related to Betaproteobacteria (59\%), whereas in order of abundance, the second group was Alphaproteobacteria (36\%) and the third group was
Gammaproteobacteria (5\%) (Fig. 6). Ten TGGE bands were reamplified and sequenced from the TGGE gels corresponding to the dominant Nitrosomonas populations in the partial-SHARON bioreactor (Table 3). Five of these were closest to N. eutropha and five to N. europaea. Three sequences were related to Diaphorobacter in the TGGE gels.

In conclusion, the results of this experiment demonstrated that Proteobacteria and members of the genus Nitrosomonas dominated the composition of the bacteria communities of the submerged-biofilter partial-SHARON bioreactor at an HRT of 0.5 day. However, nitrite-oxidizing bacteria such as Nitrobacter were not detected in the TGGE gels.

\section{Study of biofilms formed at an HRT of 0.4 day}

In the second experiment, which was performed in the partial-SHARON bioreactor at an HRT of 0.4 day, the Pearson coefficient (Fig. 4) showed only one cluster of bacteria, which clustered at $80 \%$ similarity. This result clearly indicates that there was less variation in the samples over time. Interestingly, the bands belonging to bacteria, such as Roseobacter sp. (Band 32) or Burkholderia sp. (band 50) disappeared, depending on the operating time. However, other microorganisms such as Nitrosospira sp. (band 10), Nitrosomonas sp. (band 10) and Paracoccus sp. (band 46) increased in abundance.

According to Hiroaki and Hiroshi [24], Paracoccus sp. is a common bacterium in wastewater treatment bioreactors with an important role in nitrogen removal. On the other hand, several bands had a high intensity level. This was the case of bands 31 (Vibrio sp.), 45 (Rhodobacter sp.), and 46 (Catellibacterium sp.), among others. The increasingly high intensity of these bands indicates that the development of these bacteria was favored by these conditions [25-27].

A total of 14 bands selected from the TGGE fingerprints targeting bacteria were successfully amplified and sequenced (Table 4). These bands corresponded to the dominant bacteria populations in the partial-SHARON bioreactor. The main group of identifiable TGGE bands was related to Proteobacteria and specifically to Alphaproteobacteria (56\%), Betaproteobacteria $(40 \%)$ and Delta-Protobacteria (4 \%) (Fig. 6). Four TGGE bands were reamplified and sequenced from the TGGE gels corresponding to the dominant ammonium-oxidizing bacteria populations (Nitrosospira, Nitrosomonas and Nitrosovibrio) in a partial-SHARON bioreactor (Table 4). In these experiments, Nitrosospira sp. and Nitrosovibrio sp. were detected as a normal microbiota in the bioreactor working at an HRT of 0.4 day. However, these microorganisms were not identified in the TGGE gels when the bioreactor was operating at an HRT of 0.5 day. In all likelihood, when the HRT of the partial-SHARON bioreactor was reduced 
Table 3 Bacteria obtained from the NCBI database from the sequencing of the bands extracted in experiment 1 (HRT 0.5 day)

\begin{tabular}{|c|c|c|c|c|}
\hline $\begin{array}{l}\text { No. band } \\
\text { identification }\end{array}$ & $\begin{array}{l}\text { Identities } \\
\text { (bp) }\end{array}$ & $\%$ similarity & Experiment 1: name sequence reference & Phylogenetic class \\
\hline \multirow[t]{2}{*}{1} & \multirow[t]{2}{*}{97} & 96 & HQ113216.1 Hydrogenophaga sp. CL-9.06 & Betaproteobacteria \\
\hline & & 96 & GU300152.1 Diaphorobacter oryzae strain 3R2-14 & Betaproteobacteria \\
\hline \multirow[t]{2}{*}{3} & \multirow[t]{2}{*}{85} & 100 & GQ284427.1 Acidovorax delafieldii strain THWCSN39 & Betaproteobacteria \\
\hline & & 100 & U51105.1 Denitrifying $\mathrm{Fe}<\mathrm{II}>$-oxidizing bacteria & Betaproteobacteria \\
\hline \multirow[t]{2}{*}{4} & \multirow[t]{2}{*}{83} & 100 & M96402.1 Nitrosomonas eutropha & Betaproteobacteria \\
\hline & & 100 & HM446362.1 Nitrosomonas europaea strain PD60 & Betaproteobacteria \\
\hline \multirow[t]{2}{*}{5} & \multirow[t]{2}{*}{109} & 100 & M96402.1 Nitrosomonas eutropha $16 \mathrm{~S}$ ribosomal RNA & Betaproteobacteria \\
\hline & & 100 & AY856378.1 Nitrosomonas sp. CNS332 16S ribosomal RNA & Betaproteobacteria \\
\hline \multirow[t]{2}{*}{8} & \multirow[t]{2}{*}{75} & 100 & HQ183880.1 uncultured beta proteobacterium clone De385 16S & Betaproteobacteria \\
\hline & & 98 & GU300152.1 Diaphorobacter sp. 16 s ribosomal RNA & Betaproteobacteria \\
\hline \multirow[t]{2}{*}{11} & \multirow[t]{2}{*}{92} & 100 & M96402.1 Nitrosomonas eutropha $16 \mathrm{~S}$ ribosomal RNA & Betaproteobacteria \\
\hline & & 100 & HM446362.1 Nitrosomonas europaea strain PD60 & Betaproteobacteria \\
\hline \multirow[t]{2}{*}{12} & \multirow[t]{2}{*}{83} & 100 & HM921137.1 uncultured bacterium clone ar2e1016 & Betaproteobacteria \\
\hline & & 100 & HM001269.1 Methylophilus glucoseoxidans strain B & Betaproteobacteria \\
\hline \multirow[t]{2}{*}{13} & \multirow[t]{2}{*}{91} & 100 & HM124369.1 Rhodobacter sp. 16-62 16S ribosomal RNA & Alphaproteobacteria \\
\hline & & 100 & EU652478.1 Catellibacterium sp. JPB-2.07 16S ribosomal RNA & Alphaproteobacteria \\
\hline \multirow[t]{2}{*}{14} & \multirow[t]{2}{*}{107} & 100 & HQ385754.1 Variovorax sp. 2C1-21 16S & Betaproteobacteria \\
\hline & & 100 & EF203908.1 Variovorax paradoxus isolate DB1 & Betaproteobacteria \\
\hline \multirow[t]{2}{*}{21} & \multirow[t]{2}{*}{98} & 100 & HQ259687.1 Pseudacidovorax sp. A14(2010) & Betaproteobacteria \\
\hline & & 100 & AF384190.1 Aquaspirillum sp. TG27 & Betaproteobacteria \\
\hline \multirow[t]{2}{*}{22} & \multirow[t]{2}{*}{98} & 100 & HQ259687.1 Pseudacidovorax sp. A14(2010) & Betaproteobacteria \\
\hline & & 100 & AF384190.1 Aquaspirillum sp. TG27 & Betaproteobacteria \\
\hline \multirow[t]{2}{*}{25} & 125 & 97 & AJ245760 uncultured beta proteobacterium partial 16S rRNA & Betaproteobacteria \\
\hline & 124 & 97 & JN217090 uncultured bacterium clone S252 16S ribosomal RNA & Betaproteobacteria \\
\hline 26 & 113 & 100 & GU980069.1 uncultured bacterium clone HKTJ485 & Betaproteobacteria \\
\hline & & 100 & EU542425.2 uncultured bacterium clone Er-MS-1 & Betaproteobacteria \\
\hline 27 & 83 & 100 & M96402.1 Nitrosomonas eutropha $16 \mathrm{~S}$ ribosomal RNA & Betaproteobacteria \\
\hline & & 100 & HM446362.1 Nitrosomonas europaea strain PD60 & Betaproteobacteria \\
\hline 28 & 97 & 100 & HQ183880.1 uncultured beta proteobacterium clone De385 & Betaproteobacteria \\
\hline & 96 & 98 & GU300152.1 Diaphorobacter oryzae strain 3R2-14 & Betaproteobacteria \\
\hline 30 & 96 & 100 & M96402.1 Nitrosomonas eutropha $16 \mathrm{~S}$ ribosomal RNA & Betaproteobacteria \\
\hline & & 100 & HM446362.1 Nitrosomonas europaea strain PD60 & Betaproteobacteria \\
\hline 35 & 92 & 100 & EU445263.1 Agrobacterium tumefaciens isolate EFLRI 121 & Alphaproteobacteria \\
\hline & & 100 & AJ784210.1 Rhizobium sp. P033 partial 16S rRNA gene & Alphaproteobacteria \\
\hline 37 & 98 & 100 & GU574708.1 Parvibaculum sp. EPR92 & Alphaproteobacteria \\
\hline & & 100 & FJ528267.1 Rhizobium sp. Cs218 & Alphaproteobacteria \\
\hline 38 & 95 & 95 & GQ351376.1 uncultured bacterium isolate DGGE gel band & Alphaproteobacteria \\
\hline 39 & 75 & 100 & X87274.1 B.diminuta 16S rRNA gene & Alphaproteobacteria \\
\hline & & 100 & U63935.1 Caulobacter sp. 16S ribosomal RNA gene & Alphaproteobacteria \\
\hline 40 & 76 & 100 & GU949635.1 uncultured bacterium clone 4EU1038B12 & Alphaproteobacteria \\
\hline & 73 & 100 & EU256442.1 Mesorhizobium mediterraneum strain CCBAU & Alphaproteobacteria \\
\hline 41 & 84 & 100 & GU420646.1 Defluvibacter lusatiensis clone AW171 & Alphaproteobacteria \\
\hline & & 100 & GU415542.1 Ochrobactrum anthropi clone AW034 & Alphaproteobacteria \\
\hline 42 & 99 & 100 & EU635967.1 uncultured bacterium isolate DGGE band 13 & Alphaproteobacteria \\
\hline & 98 & 98 & FJ587218.1 Pseudoxanthobacter sp. & Alphaproteobacteria \\
\hline 47 & 90 & 100 & HM629504.1 Escherichia coli strain BAB-286 & Gammaproteobacteria \\
\hline & 89 & 98 & HM629493.1 Salmonella enterica strain & Gammaproteobacteria \\
\hline
\end{tabular}


Fig. 6 Phylogenetic classes (\%) detected in the partialSHARON bioreactor at HRT of 0.5 day (a) and HRT of 0.4 day (b) analyzed by PCR-TGGE method
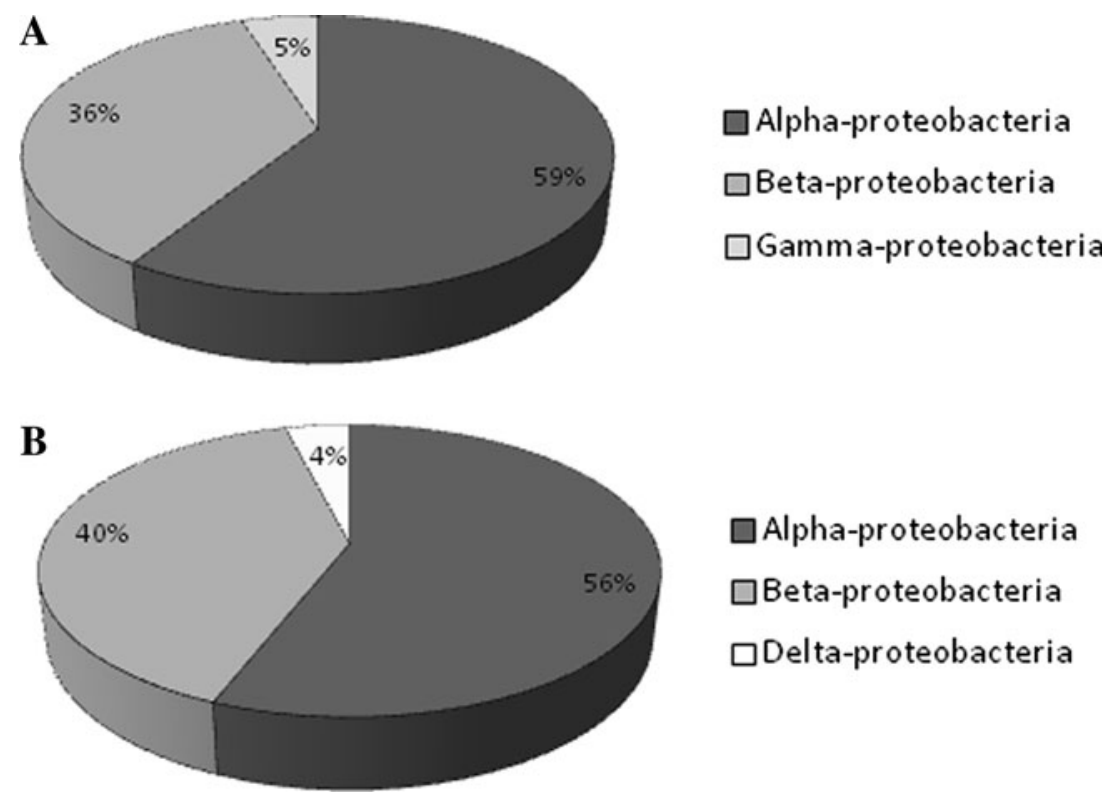

Alpha-proteobacteria

Beta-proteobacteria

Delta-proteobacteria

Table 4 Bacteria obtained from the NCBI database from the sequencing of the bands extracted in experiment 2 (HRT 0.4 day)

\begin{tabular}{|c|c|c|c|c|}
\hline $\begin{array}{l}\text { No. band } \\
\text { identification }\end{array}$ & $\begin{array}{l}\text { Identities } \\
\text { (bp) }\end{array}$ & $\begin{array}{l}\% \\
\text { similarity }\end{array}$ & Experiment 2: name sequence reference & Phylogenetic class \\
\hline \multirow[t]{2}{*}{9} & \multirow[t]{2}{*}{78} & 98 & X84662.1 Nitrosospira sp. 16S rRNA gene & Betaproteobacteria \\
\hline & & 98 & M96405.1 Nitrosovibrio tenuis $16 \mathrm{~S}$ ribosomal RNA & Betaproteobacteria \\
\hline \multirow[t]{2}{*}{10} & \multirow[t]{2}{*}{95} & 100 & M96402.1 Nitrosomonas eutropha $16 \mathrm{~S}$ ribosomal RNA & Betaproteobacteria \\
\hline & & 100 & HM446362.1 Nitrosomonas europaea strain PD60 & Betaproteobacteria \\
\hline \multirow[t]{2}{*}{15} & \multirow[t]{2}{*}{99} & 100 & FJ222605.1 Albidovulum sp. S1K1 & Alphaproteobacteria \\
\hline & & 100 & HM705035.1 uncultured bacterium clone GB7N87002DSSDY & Alphaproteobacteria \\
\hline 16 & 65 & 100 & GQ853528.1 uncultured Ochrobactrum sp. & Alphaproteobacteria \\
\hline 17 & 74 & 100 & EF195167.1 Alcaligenes sp. RG-03/06 16S & Betaproteobacteria \\
\hline \multirow[t]{2}{*}{24} & \multirow[t]{2}{*}{70} & 100 & HM001269.1 Methylophilus glucoseoxidans strain B & Betaproteobacteria \\
\hline & & 100 & GQ411499.1 Methylophilus methylotrophus strain NBCS15 & Betaproteobacteria \\
\hline \multirow[t]{2}{*}{31} & 98 & 100 & EF079668.1 Thiobacillus sp. K6.2 & Betaproteobacteria \\
\hline & 97 & 98 & FM957479.1 Vibrio sp. MY-2008-U67 & Betaproteobacteria \\
\hline \multirow[t]{2}{*}{32} & 78 & 100 & AM710422.1 uncultured bacterium partial 16S rRNA gene & Alphaproteobacteria \\
\hline & 79 & 98 & AY576768.1 Roseobacter sp. 3X/A02/234 & Alphaproteobacteria \\
\hline 33 & 87 & 95 & AM922185.1 Sphingopyxis sp. Sulf-541 & Alphaproteobacteria \\
\hline \multirow[t]{2}{*}{34} & 94 & 98 & HM687288.1 uncultured bacterium clone GB7N87001BDHL1 & Alphaproteobacteria \\
\hline & 93 & 97 & HQ596322.1 Bradyrhizobium sp. CNX333 & Alphaproteobacteria \\
\hline \multirow[t]{2}{*}{45} & \multirow[t]{2}{*}{82} & 100 & $100 \%$ HM124369.1 Rhodobacter sp. 16-62 & Alphaproteobacteria \\
\hline & & 100 & $100 \%$ EU652478.1 Catellibacterium sp. JPB-2.07 & Alphaproteobacteria \\
\hline 46 & 91 & 100 & $100 \%$ HM124369.1 Rhodobacter sp. 16-62 16S ribosomal RNA gene & Alphaproteobacteria \\
\hline 52 & 52 & 100 & $100 \%$ GQ183899.1 Geothermobacter sp. & Deltaproteobacteria \\
\hline
\end{tabular}

from 0.5 to 0.4 day, this caused the biodiversity of this specialized microbial group to increase.

In conclusion, the results of this experiment demonstrated that Proteobacteria and members of the genus Nitrosomonas, Nitrosospira, and Nitrovibrio dominated the composition of the bacterial community of the submergedbiofilter partial-SHARON bioreactor at an HRT of 0.4 day. However, as previously mentioned, nitrite-oxidizing bacteria such as Nitrobacter were not detected in the TGGE gels. 
Comparison of the bacterial diversity obtained in experiment 1 (HRT of 0.5 day) and experiment 2 (HRT of 0.4 day)

A comparison of the results of the two experiments seems to indicate that the modification of the HRT affected the bacterial diversity of the biofilms formed in a partialSHARON system with a submerged filter. In the experiment performed at an HRT of 0.5 day, bacterial diversity was significantly reduced when the bioreactor operated in stable conditions (after 5 days). In fact, fewer than 10 bands were observed, probably as a consequence of the high level of specific ammonium-oxidizing bacteria. In these conditions, $100 \%$ ammonium was converted into nitrite, and thus all the microbial population was obliged to compete for ammonium. However, in experiment 2, in which the HRT of the bioreactor was adjusted to 0.4 day, the microbial biodiversity was extremely heterogeneous. This result could explain the evenness observed in the bacterial community. Since $65.5 \%$ of the ammonium was

Table 5 Average range-weighted richness $\left(R_{\mathrm{r}}\right)$ and functional organization $\left(F_{\mathrm{o}}\right)$ indices of the bacterial communities in partial-SHARON bioreactor samples from the two experiments in this study

\begin{tabular}{lllll}
\hline Experiment & No. of samples & $R_{\mathrm{r}}$ & $F_{\mathrm{o}}$ & Statistic program \\
\hline 1 & 8 & $2^{*}$ & 49 & ANOVA analysis \\
2 & 8 & $5^{*}$ & 43 & ANOVA analysis \\
\hline
\end{tabular}

* Statistically significant difference (Student's $t$ test, $p<0.05$ ) converted to nitrite, this led to a less specialized bacterial community (see Figs. 4, 5). These data are in consonance with the results reported in Logemann et al. [28], and Marzorati et al. [16].

The comparison of the results obtained in the two experiments highlighted the similarity of different bands. This indicated the presence of certain microorganisms, such as Nitrosomonas sp., which were constant in both experiments (see Tables 3, 4). This fact is hardly surprising since this microbial group can be regarded as predominant in an extreme environment with a high dilution rate, a temperature of $36^{\circ} \mathrm{C}$, and a high ammonia concentration [29]. These results suggest the significance of Nitrosomonas sp. in the biofilm formed in the submerged-filter partial-SHARON system and its important role in the biotransformation of ammonium into nitrite in this wastewater treatment biotechnology [22, 23].

Image analysis with Gel Compar II detected a total of 66 unique band classes in the TGGE fingerprints of bacteria among the 52 bands detected (Fig. 5). A total of 38 bands selected from the TGGE fingerprints targeting bacteria were successfully amplified and sequenced, representing the $73 \%$ of the bands chosen for sequencing (Tables 3,4).

The richness range-weighted $\left(R_{\mathrm{r}}\right)$ indices [14] showed significant differences with ANOVA analysis $(p<0.05)$ in both experiments (Table 5). The $R_{\mathrm{r}}$ of experiment 2 (HRT of 0.4 day) displayed higher average values than those of experiment 1 (HRT of 0.5 day). Construction of the ParetoLorenz curves of the bacterial community profiles in
Fig. 7 SEM of the carriers used in a submerged-filter partialSHARON bioreactor in different conditions. a Microscopic images of day 1 with an HRT of 0.5 (sample 1A); b microscopic images of day 8 with an HRT of 0.5 (sample 8A); c microscopic images of day 1 with an HRT of 0.4 (sample 1B); $\mathbf{d}$ microscopic images of day 8 with an HRT of 0.4 (sample 8B)
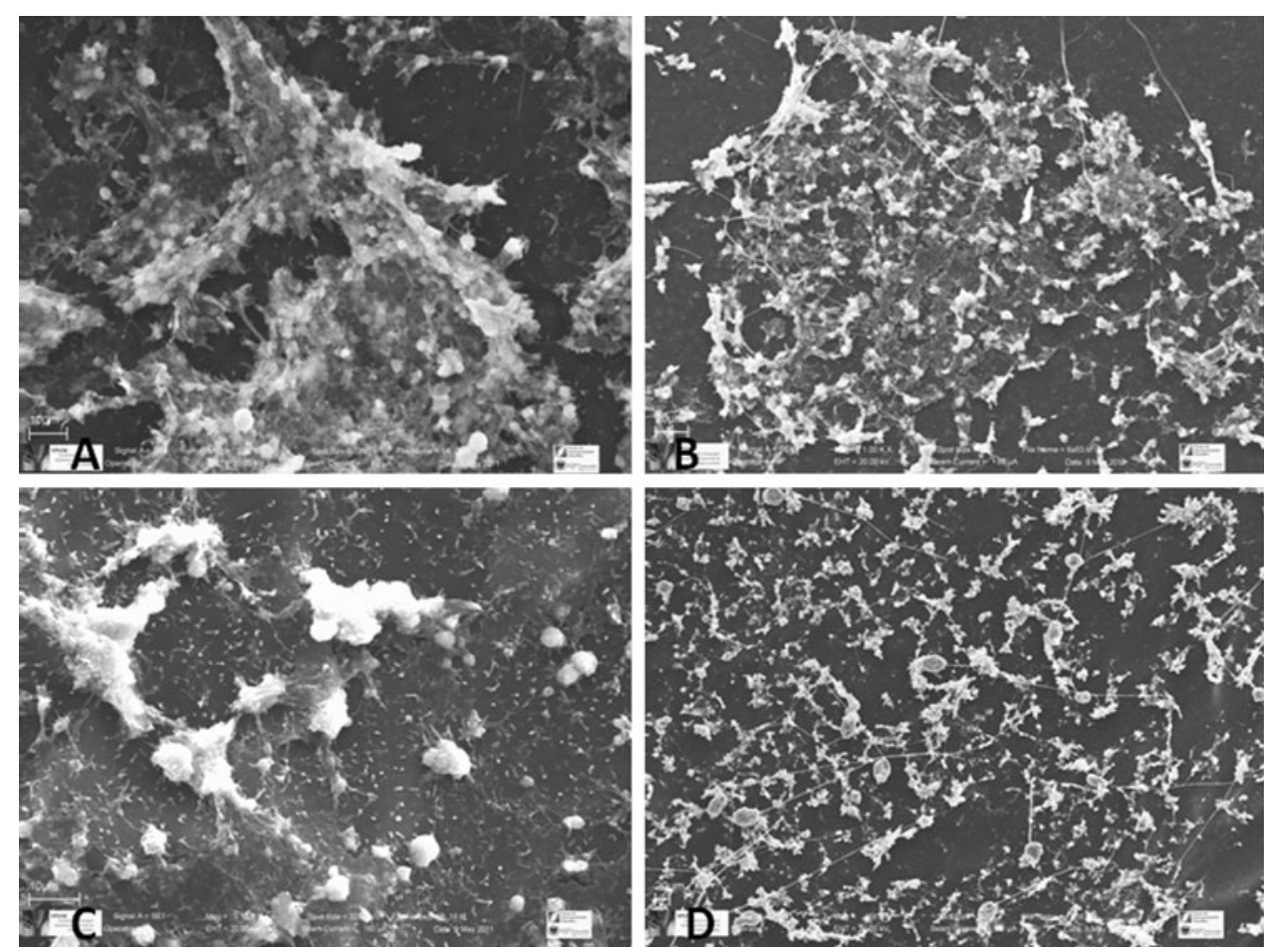
experiment 2 permitted the calculation of the functional organization $\left(F_{\mathrm{o}}\right)$ indices [14].

$F_{\mathrm{o}}$ indices of 49 and $43 \%$ were obtained in the experiments 1 and 2, respectively. According to Marzorati et al. [16], $F_{\mathrm{o}}$ index values of around $45 \%$ represent a balanced community, potentially able to preserve its functionality under changing environmental conditions. Obviously, these results reflect the higher specialization of the bacterial community in the submerged-filter partial-SHARON bioreactor and its capacity to adapt to different working conditions.

\section{Scanning electronic microscopy}

The colonization of the plastic carrier, used in the construction of the submerged-filter partial-SHARON bioreactor with an HRT of 0.5 and 0.4 day, was studied after 1 and 8 days (see Fig. 7). The results showed a rapid colonization of the carrier with the formation of a complex and heterogeneous biofilm. At the end of both experiments, the samples were found to contain a large number of different morphological types as well as filamentous bacteria. These results coincide with the data previously reported in this paper, which suggest the presence of complex microbiota in both experiments, independently of the HRT used in the wastewater system.

\section{Conclusions}

The results obtained in our study within the context of recent research in the field lead to the conclusion that the HRT affects the functioning of a partial-SHARON bioreactor built with submerged-filter technology. This is reflected in different levels of biotransformation of ammonium into nitrite. This signifies that the application of submerged-filter technology to the partial-SHARON system increases the biotransformation of ammonium into nitrite, in comparison to other technologies such as a fluidized bed. Moreover, our results show that the HRT affects the microbial diversity of biofilms formed in a partial-SHARON bioreactor, possibly as a result of the different nutritional conditions that arise when this variable is modified.

On the other hand, the use of an HRT of 0.5 day determines the formation of highly specialized biofilms (mainly by Nitrosomonas sp.), which are effective in the biotransformation of ammonium into nitrite. On the contrary, the use of an HRT of 0.4 day, determines the formation of more heterogeneous biofilms that allow a closer ammonium/nitrite ratio, which is more effective for the combined development of partial-SHARON/Anammox systems.
Acknowledgments This research was funded by the Department of Innovation, Science and Enterprise of the Regional Government of Andalusia, Spain (P09-RNM-5412). We would also like to thank the MITA group, the Instituto de Parasitología y Biología Molecular López Neyra (CSIC, Granada, Spain) and the Centro de Instrumentación Cientifica (CIC, Granada, Spain) for their valuable cooperation.

\section{References}

1. Metcalf \& Eddy (2003) Wastewater engineering, treatment and reuse, 4th edn. McGraw-Hill, New York

2. Mosquera-Corral A, González F, Campos JL, Méndez R (2005) Partial nitrification in a Sharon reactor in the presence of salts and organic carbon compounds. Process Biochem 40:3109-3118

3. Mulder MW, Van Loosdrecht MCM, Hellinga C, Kempen R (2001) Full-scale application of the SHARON process for treatment of rejection water of digested sludge dewatering. Water Sci Technol 43(11):127-134

4. Calderón K, Rodelas B, Cabirol N, González-López J, Noyola A (2011) Analysis of microbial communities developed on the fouling layers of a membrane-coupled anaerobic bioreactor applied to wastewater treatment. Bioresour Technol 102(7):4618-4627

5. Gómez-Silván C, Molina-Muñoz M, Poyatos JM, Ramos A, Hontoria E, Rodelas B, González-López J (2010) Structure of archaeal communities in membrane-bioreactor and submergedbiofilter wastewater treatment plants. Bioresour Technol 101:20962105

6. Hellinga C, Schellen AAJC, Mulder JW, Van Loosdrecht MCM, Heijnen JJ (1998) The SHARON-process: an innovative method for nitrogen removal from ammonium rich wastewater. Water Sci Technol 37(1):135-142

7. Jetten MSM, Schmid MA, Schmidt I, Wubben M, van Dongen L, Abma W, Sliekers OA, Revsbech NP, Beaumont B, Ottosen LM, Volcke E, Laanbroek HJ, Campos-Gomez JL, Cole JA, van Loosdrecht MCM, Mulder JW, Fuerst JA, Richardson D, van de Pas KT, Mendez-Pampin R, Third KM, Cirpus IY, van Spanning RJM, Nielsen LP, Op den Camp HJM, Schultz C, Gundersen JK, Vanrolleghem P, Strous M, Wagner M, Kuenen JG (2002) Implementation of EU guidelines for nitrogen removal by improved control and application of new nitrogen-cycle bacteria. Rev Environ Sci Biotechnol 1:51-63

8. Van Dongen U, Jetten MSM, Van Loosdrecht MCM (2001) The SHARON-ANAMMOX process for treatment of ammonium rich wastewater. Water Sci Technol 44(1):153-160

9. Molina-Muñoz M, Poyatos JM, Sánchez-Peinado MM, Hontoria E, González-López J, Rodelas B (2009) Microbial community structure and dynamics in a pilot-scale submerged membrane bioreactor aerobically treating domestic wastewater under real operation conditions. Sci Total Environ 407:3994-4003

10. Gómez-Villalba B, Calvo C, Vilchez R, González-López J, Rodelas B (2006) TGGE analysis of the diversity of ammoniaoxidizing and denitrifying bacteria in submerged filter biofilms for the treatment of urban wastewater. Appl Microbiol Biotechnol 72(2):393-400

11. Liang Z, Liu J (2007) Control factors of partial nitritation for landfill leachate treatment. J Environ Sci 19:523-529

12. Vilar A, Eiroa M, Kennes C, Veiga MC (2010) The SHARON process in the treatment of landfill leachate. Water Sci Technol 61(1):47-52

13. Gonzalez-Martinez A, Poyatos JM, Hontoria E, Gonzalez-Lopez J, Osorio F (2011) Treatment of effluents polluted by nitrogen with new biological technologies based on autotrophic nitrification-denitrification processes. Recent Pat Biotechnol 5(2):74-84 
14. Van Hulle SWH, Van Den Broeck S, Maertens J, Villez K, Donckels BMR, Schelstraete G, Volcke EIP, Vanrolleghem PA (2005) Construction start-up and operation of a continuously aerated laboratory-scale SHARON reactor in view of coupling with an Anammox reactor. Water SA 31(3):327-334

15. Peng Y, Zhu G (2006) Biological nitrogen removal with nitrification and denitrification via nitrite pathway. Appl Microbiol Biotechnol 73:15-26

16. Marzorati M, Wittebolle L, Boon N, Daffonchio D, Verstraete W (2008) How to get more out of molecular fingerprints, practical tools for microbial ecology. Environ Microbiol 10:1571-1581

17. Altschul SF, Madden TL, Schaffer AA, Zhang JH, Zhang Z, Miller W, Lipman DJ (1997) Gapped BLAST and PSI-BLAST: a new generation of protein database search programs. Nucleic Acids Res 25:3389-3402

18. Van Loosdrecht MCM (2004) Recent development on biological wastewater nitrogen removal technologies. In: Proceedings of the international conference on wastewater treatment for nutrient removal and reuse (ICWNR'04). Pathumthani, Thailand, January 26-29

19. Jetten MSM, Horn SJ, Van Loosdrecht MCM (1997) Towards a more sustainable municipal wastewater treatment system. Water Sci Technol 35:171-180

20. Khan ST, Hiraishi A (2002) Diaphorobacter nitroreducens gen nov, sp nov, a poly(3-hydroxybutyrate)-degrading denitrifying bacterium isolated from activated sludge. J Gen Appl Microbiol 48(6):299-308

21. Anshuman A, Khardenavis AK, Hemant JP (2007) Simultaneous nitrification and denitrification by diverse Diaphorobacter sp. Appl Microb Cell Physiol 77(2):403-409
22. Poth M, Focht DD (1985) ${ }^{15} \mathrm{~N}$ kinetic analysis of $\mathrm{N}_{2} \mathrm{O}$ production by Nitrosomonas europaea: an examination of nitrifier denitrification. Appl Environ Microbiol 49:1134-1141

23. Schmidt I, Bock E (1997) Anaerobic ammonia oxidation with nitrogen dioxide by Nitrosomonas eutropha. Arch Microbiol 167:106-111

24. Hiroaki U, Hiroshi S (1996) Nitrogen removal by tubular gel containing Nitrosomonas europaea and Paracoccus denitrificans. Appl Environ Microbiol 62(11):4224-4228

25. Huang JS, Wu CS, Jih CG, Chen CT (2001) Effect of addition of Rhodobacter $\mathrm{sp}$. to activated-sludge reactors treating piggery wastewater. Water Res 35(16):3867-3875

26. Liu Y, Xu C-J, Jiang J-T, Liu Y-H, Song X-F, Li H, Liu Z-P (2004) Catellibacterium aquatile sp. nov., isolated from fresh water, and emended description of the genus Catellibacterium Tanaka et al. 2004. Int J Syst Evol Microbiol 60:2027-2031

27. Xiaoyan Y, XIaochang C, Yonghun W, Liu J (2011) Study of the variation of ecotoxicity at different stages of domestic wastewater treatment using Vibrio qinghaiensis sp.-Q67. Appl Environ Microbiol 190:1-3

28. Logemann S, Schantl J, Bijvank S, van Loosdrecht M, Kuenen J, Jetten M (1998) Molecular microbial diversity in a nitrifying reactor system without sludge retention. FEMS Microbiol Ecol 27:239-249

29. Stehr G, Boettcher B, Dittberner P, Rath G, Koops HP (1995) The ammonia-oxidizing nitrifying population of the River Elbe estuary. FEMS Microbiol Ecol 17:177-186 